\title{
Characterization of land subsidence induced by groundwater withdrawals in Wenyu River alluvial fan, Beijing, China
}

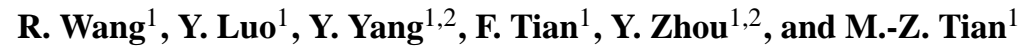 \\ ${ }^{1}$ Beijing Institute of Hydrogeology and Engineering Geology, Beijing, China \\ ${ }^{2}$ School of Earth \& Space Sciences,Peking University, Beijing, China \\ Correspondence to: R. Wang (happywangrong@126.com) \\ Published: 12 November 2015
}

\begin{abstract}
The Beijing plain area has suffered from severe land subsidence owing to groundwater overdraft. A major example is the Wenyu River alluvial fan in the Beijing plain area. This area has experienced as much as $10 \mathrm{~m}$ of land subsidence through 2000s. An integrated subsidence-monitoring program, including borehole extensometer and multilayer monitoring of groundwater, has been designed to meet the needs of monitoring land subsidence in this region. This work has allowed us to characterize land subsidence and understand the mechanical properties of the strata. The analysis results show the development of the land subsidence in this area is consistent with water-level change. The major strata contributing to compression deformation are MidPleistocene stratum which contributed around $70 \%$ of total subsidence. The shallow stratum and deep stratum show elastic mechanical behavior the intermediate stratum exhibit elastic-plastic mechanical behavior.
\end{abstract}

\section{Introduction}

Land subsidence, as a non-compensable loss of environment and resources, is regional geological disaster caused by the damage of geological environment system. It can induce a series of other environmental hazards to form disaster chains (Bawden et al., 2001). China also suffers serious land subsidence. A long sequences of land subsidence monitoring data was used to analyze the deformation behaviour of soil in Shanghai (Zhang et al., 2006), Tianjin (Dong et al., 2008), Suzhou, Xi' an and Changzhou (Shi et al., 2006), China. The deformation behavior of compression layer is also analysed at the rapidly development stage in Beijing (Tian et al., 2012), and, the study of the relationship between land subsidence and groundwater is also carried out at the same time (Yang et al., 2013). The previous research is insufficiency in some respects such as the different layer characters of land subsidence and the relationship between land subsidence and the groundwater level change with the same monitoring data in the same area, and the reason of the compression characteristic emerged through multiple factors and multi-angle analysis. However, it is critical for the regulation of land subsidence and the optimization planning of groundwater pumping.

The paper takes Wenyu Alluvial Fan as the study area, which contains the Baxianzhuang subsidence region. It has complicated compression types and varied influence factors, and acts as one of the most serious and representative subsidence regions in Beijing currently.

\section{Development characteristics of land subsidence}

\subsection{Delamination development characteristics}

Since 2004, seven land subsidence monitoring station has been built to obtain the compression in different layers and the groundwater level change in Beijing plain area. The groundwater level monitoring wells and borehole extensometer can provide the compression of aquifer system and the change of pore pressure, which is useful for understanding the hydrology and mechanics characteristics of the hydrogeological unit in different depth. There are ten borehole extensometer wells in Baxianzhuang monitoring station. The 
Table 1. Monitoring land subsidence list in Baxianzhuang.

\begin{tabular}{lc}
\hline ID & Layer $(\mathrm{m})$ \\
\hline D4-1 & $304-333$ \\
D4-2 & $259-278$ \\
D4-3 & $211-235$ \\
D4-4 & $147-195$ \\
D4-5 & $60-107$ \\
D4-6 & $13.5-23$ \\
\hline F4-1 & below 304 \\
F4-2 & $262.00 \sim 304$ \\
F4-3 & $235.00 \sim 262$ \\
F4-4 & $197.00 \sim 235$ \\
F4-5 & $144.00 \sim 197$ \\
F4-6 & $108.00 \sim 144$ \\
F4-7 & $83.00 \sim 108$ \\
F4-8 & $59.00 \sim 83$ \\
F4-9 & $24.00 \sim 59$ \\
F4-10 & $2.00 \sim 24$ \\
\hline
\end{tabular}

Table 2. Stratums compaction of different geologic age.

\begin{tabular}{lcc}
\hline $\begin{array}{l}\text { Stratigraphic } \\
\text { age }\end{array}$ & $\begin{array}{l}\text { The depth } \\
\text { of bottom } \\
\text { boundary }\end{array}$ & $\begin{array}{c}\text { Compression } \\
\text { proportion }\end{array}$ \\
\hline Holocene, Late Pleistocene & 37 & $<1 \%$ \\
Middle Pleistocene & 135 & $70 \%$ \\
Early Pleistocene & 350 & $29 \%$ \\
\hline
\end{tabular}

monitoring layers of borehole extensometer and groundwater level are showed in Table 1.

The borehole extensometer result showed that the major compression layer is the Middle Pleistocene strata, which accounts for about $70 \%$. The most dominant compression layer has a depth of 108-144 m, which can account for $34.62 \%$ of the total, followed by the depth of $24-59,59-83,83-108$, 144-197, and 197-235 m with 12.40, 7.66, 15.31, 14.52, and $11.02 \%$ compression amount respectively. The compression of other strata is only $2 \%$.

Different geological age has great impact on the Sedimentary thickness and consolidation status. According the Paleomagnetic, pollen and $\mathrm{C}^{14}$ of engineering geology hole in Baxianzhuang, the interface of Quaternary chronostratigraphic can be determined. Combined with the measured subsidence of different layer, the bottom boundary of Holocene and Late Pleistocene has a depth of $37 \mathrm{~m}$ below the surface, whose contribution is small for the subsidence. The bottom boundary of Middle Pleistocene has a depth of $135 \mathrm{~m}$, and it is the major contribution layer to the subsidence which can account for about $70 \%$. The bottom boundary of Early Pleistocene has a depth of $350 \mathrm{~m}$, and the subsidence can account for about $29 \%$.

\subsection{Groundwater withdrawal and land subsidence}

There are five aquifer groups in the Quaternary aquifer system of the study area (Liu et al., 2007). Due to the low-quality of groundwater, the groundwater withdrawal of first aquifer group is small and the groundwater level drops slowly, and in some areas the groundwater level even rises. The second aquifer group has a large exploitation quantity due to the agricultural irrigation, and the groundwater level shows seasonal changes. The water of third aquifer group is mainly used as domestic and industrial water, and the groundwater level drops quickly owing to the large amount of groundwater exploitation. The forth pumping is mainly for domestic water and partly for industrial water. There is little groundwater pumping in the fifth group.

The main pumping strata is the third layer, which can account for $75 \%$, and the corresponding compression is $50 \%$ of the total. The second layer accounts for $21.64 \%$ of the total pumping, and the compression of this strata is $35.36 \%$. Therefore, groundwater exploitation is an important factor for land subsidence. In the same area, large water pumping in the different layer can cause large land subsidence, however, they are not directly related. There are other factors will certainly influence the compression volume and compression character.

\subsection{Groundwater regime and land subsidence}

Long-term over-exploitation of groundwater can cause significant decline of groundwater level, then lead to the decline of the pore-pressure of the overlaying soil. As a result, the water loss, consolidation and compression of soil would happen. At the same time, soil particles of aquifer layer become more closely aligned to form land subsidence.

With long series land subsidence monitoring, the groundwater level change of aquifer in different layers is compared with the trend of land subsidence of different strata. The result shows that the groundwater level is consistent with development of land subsidence. The land subsidence has an increasing state when the groundwater level has a cyclical variation. The rate of subsidence repeating is in accordance with the seasonal change of groundwater level. The accumulative subsidence is increasing fast when the groundwater level drops, and it has a delay and the rate is slow down when the groundwater level rises (shown in Fig. 1).

\section{Deformation characteristics of soil water release}

Based on the monitoring of the groundwater level and borehole extensometer, the stress-strain map is used to analyze the character of compression in different layer. It can be used to select appropriate constitutive equation and provide a scientific basis for land subsidence prediction (Burbey, 2001). The result shows that the strata in different depth has disparate compression and deformation character of soil. The 


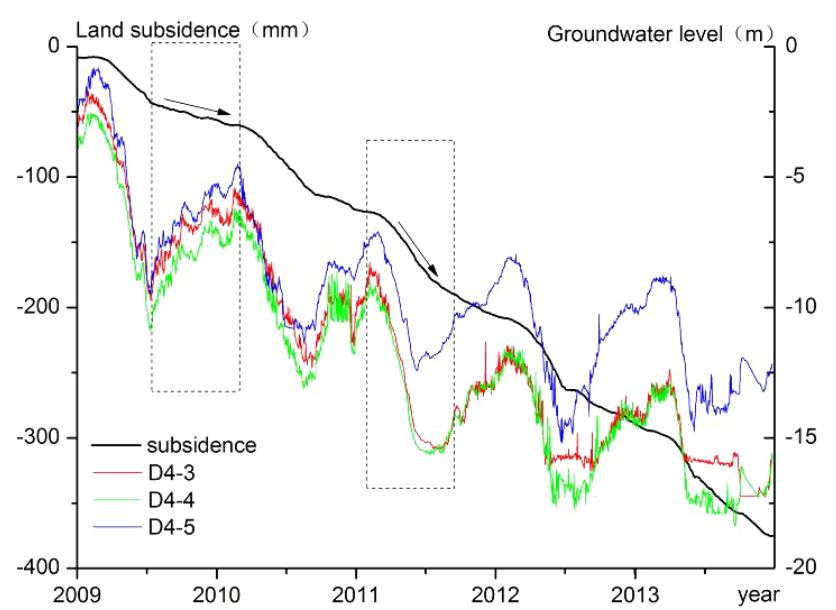

Figure 1. Relation of land subsidence and groundwater level in monitoring station.

compression of soil has elastic and elastic-plastic characteristics.

\subsection{Elastic deformation}

\subsubsection{Deformation characteristics of shallow strata}

The monitoring data of Baxianzhuang station shows that the compression of shallow strata $(0-24 \mathrm{~m})$ is small. From 2009 to 2013, the deformation is from -1 to $1 \mathrm{~mm}$ and the groundwater level is rising (Fig. 2). The result is that the level is rising slowly and there is no compression in this layer.

\subsubsection{Deep strata}

The compression of strata below $235 \mathrm{~m}$ is small in Baxianzhuang which accounts for $3.6 \%$ of the total land subsidence. The monitoring result shows that the deformation of this strata is well consistent with the groundwater level change. Along with cyclical fluctuations in the water table, the deformation also shows seasonal deformation characteristics. Since 2009, the groundwater level shows significantly periodic characteristics, and the compression period of soil also shows almost the same trend.

The confined water show a circular and cyclic quality in such depth. However, the rise value is usually less than the decline value in each cycle, which cause the continuous declination of groundwater level (Fig. 3a). Accordingly, the soil is also suffered from repeated loading and unloading effect. The stress increased is greater than the stress reduction, and the effective stress of the overall soil continued to increase. When the water level drops, the compression amount is relatively large. When the water level rises, the compression amount slowed a significantly decreasing tendency, and a slight rebound phenomenon (Fig. 3b). The stress-strain analysis indicates that there is smaller hysteresis loop appeared

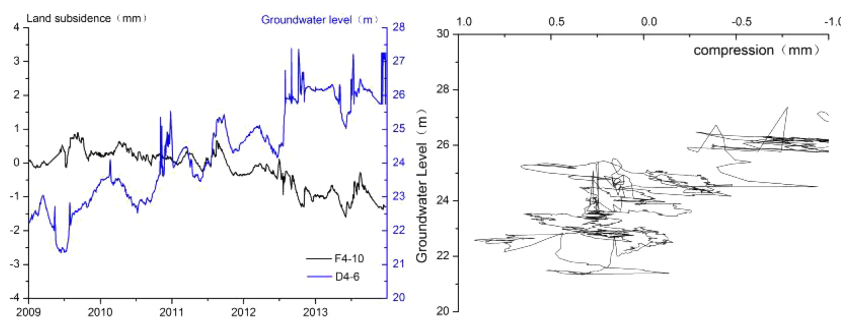

Figure 2. Soil deformation and water level of F4-10.

within the repeated loading-unloading process (Fig. 3c). The strata shows significant elastic deformation characteristics.

\subsection{Elastic-plasticity deformation}

The middle-deep strata $(24 \sim 235 \mathrm{~m})$ is the main layers studied for groundwater exploitation, the groundwater level of the aquifer system at such strata has overall decline trend. The groundwater level has significant seasonal fluctuation with the maximum amplitude up to $4 \mathrm{~m}$. At the same time, the strata is the major layer contributes to the formation of surface deformation, whose compression amount accounts for more than $95 \%$ of the total compression amount. Since 2009 , the groundwater level periodically reciprocating movements, in each cycle, the water level declined more than rise and showed an overall decline trend. It means that the effective stress of soil continues to increase, and the soil sustained to compress (Fig. 4a). Whenever the water level rises, soil compression slows down. The residual compression is greater than the rebound, and the soil shows a sustained compress trend (Fig. 4b). Stress-strain analysis showed (Fig. 4c), the water level overall continued to decline with dynamic changes, but still higher than the lowest level. There are six borehole extensometers at the depth within $24-235 \mathrm{~m}$ in the Immortals village land subsidence monitoring station With the analysis of layered subsidence and the corresponding water level monitoring, each layer has basically the same stress-strain characteristics, which is elastic-plastic deformation that dominants by the plasticity characteristics.

For normally consolidated or unconsolidated formations, its deformation mechanism can be explained on the basis of the principle of effective stress. It can be described as that drawdown increases, the pore pressure decreases, the effective stress of soil skeleton increases and land subsidence occurs. For over-consolidated formations, the driving conditions of ground subsidence is the key to study its deformation mechanism. In over-consolidated formations, the occurrence of land subsidence needs a driver such as a initial additional stress more than the over-consolidation stress, or a initial drawdown greater than the of the critical water level. 


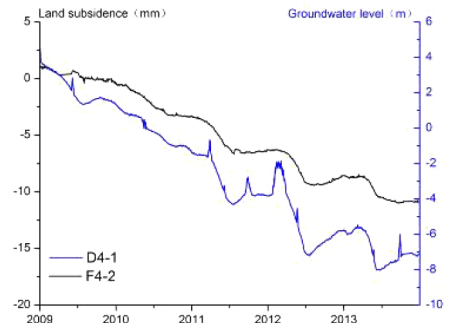

(a)

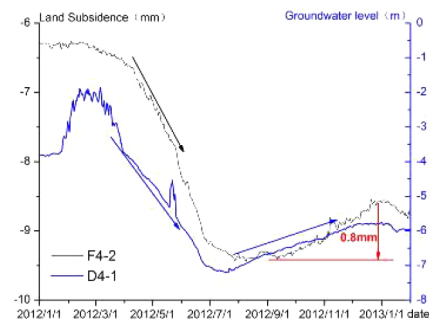

(b)

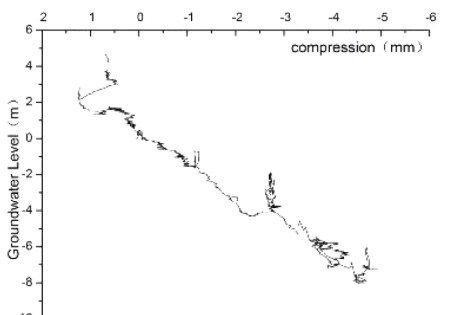

(c)

Figure 3. Soil deformation and water level of F4-2.

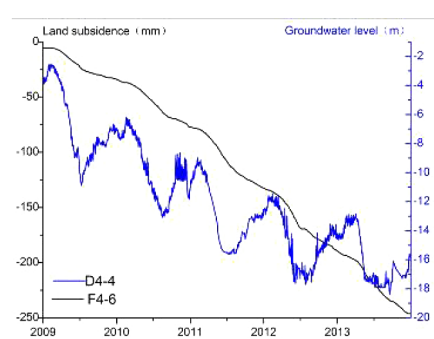

(a)

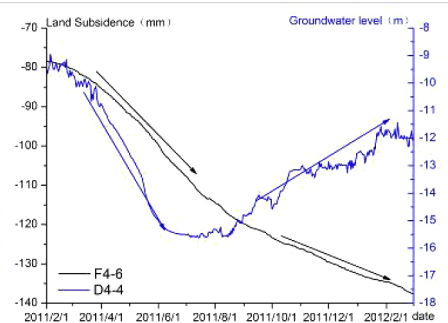

(b)

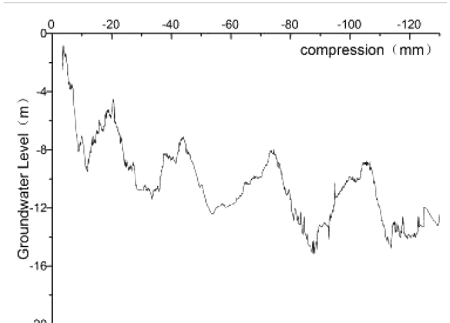

(c)

Figure 4. Soil deformation and water level of F4-6.

\section{Conclusion}

This paper focuses on the land subsidence of Baxianzhuang, and analyzes the compression characteristics of different strata and the influence factors with monitoring data of different layers. According to the geotechnical test, the deformation characteristics of aquifer system when releasing water can be acquired. The results are obtained as below.

The borehole extensometer result showed that the major compression layer is the Middle pleistocene strata, which accounts for about $70 \%$.

The compression of early Pleistocene strata is low, and the compression of strata below $200 \mathrm{~m}$ can account for $29 \%$ of the total land subsidence. Most soil is at normal consolidated or under-consolidated state and the thickness of clay is small. With the same exploitation amount, the compression of this strata is small. Therefore, it is the priority layer to pump groundwater in order to regulate land subsidence.

Acknowledgements. We thank Beijing Geology Minerals Investigation Development Bureau, China Institute of Geo-Environment for supporting our work and data processing tasks that aided our research. We are especially grateful to Ye Chao, Liu Wenchen, Liu Jiurong and our peers who have been working tirelessly on the land subsidence monitoring and prevention in Beijing Plain.

\section{References}

Bawden, G. W., Thatcher, W., Stein, R. S., Hudnut, K. W., and Peltze, G.: Tectonic constraction across Los Angeles after removal of groundwater pumping effects, Nature, 412, 812-815, 2001.

Burbey, T. J.: Stress-strain analyses for aquifer-system characterization, Groundwater, 39, 128-136, 2001.

Dong, K. G., Wang, W., Yu, Q., Zhou, J., Lu, Y., Yi, Ch. R., and Zheng, Y. P.: Ratio of soil loss to groundwater-exploitation in the Tianjin land subsidence area, Hydrogeology and Engineering Geology, 5, 76-80+91, 2008.

Liu, Y., Ye, C., and Jia, S.-M.: Division of water-bearing zones and compressible layers in Beijing's land subsidence areas, City Geology, 1, 10-15, 2007.

Shi, X. Q., Xue, Y. Q., Wu, J. Ch., Zhang, Y., Yu, J., and Zhu, J. Q.: A study of soil deformation properties of the groundwater system in the Changzhou area, Hydrogeology and Engineering Geology, 3, 1-6, 2006.

Tian, F., Guo, M., Luo, Y., Zhou, Y., and Jia, S. M.: The deformation behavior of soil mass in the subsidence area of Beijing, Geology in China, 39, 236-242, 2012.

Yang, Y., Zheng, F. D., Liu, L. C., Wang, S. F., and Wang, R.: Study on the correlation between groundwater level and ground subsidence in Beijing plain areas, Geotechical Investigation \& Surveying, 8, 44-48, 2013.

Zhang, Y., Xue, Y. Q., Ye, Sh.j., Wu, J. Ch., and Li, Q. F.: Analysis of deformation of sand strata and land subsidence based on modes of groundwater level changes in Shanghai city, The Chinese Journal of Geological Hazard and Control, 3, 103-109, 2006. 